\title{
The Covariability of Sea Surface Temperature and MAM Rainfall on East Africa Using Singular Value Decomposition Analysis
}

\author{
Exavery Kisesa Makula ${ }^{A, B}$, Marie Adolatha Umutoni ${ }^{A, C}$, Lovina Peter Japheth ${ }^{A, D}$, \\ Elias Julius Lipiki ${ }^{A, D}$, Laban Lameck Kebacho ${ }^{\mathrm{A}, \mathrm{B}}$, Paul Tilwebwa Shelleph Limbu ${ }^{\mathrm{A}, \mathrm{B}}$ \\ Received: July 18, 2020 | Revised: November 13, 2020 | Accepted: November 27, 2020 \\ doi: 10.5937/gp24-27577
}

\begin{abstract}
The study assesses the covariability of Sea Surface Temperature (SST) and March to May (MAM) rainfall variability on East Africa (EA) from 1981 to 2018. Singular Value Decomposition (SVD) analysis reveals the significant influence of SST anomalies on MAM rainfall, with covariability of $91 \%, 88.61 \%$, and $82.9 \%$ for Indian, Atlantic, and the Pacific Ocean, respectively. The Indian Ocean explains the variability of rainfall to the large extent followed by the Atlantic Ocean and the Pacific Ocean. The rainfall patterns over the EA correspond to SST variability over the western, central, and eastern Indian Ocean. Likewise, the variability of SST anomalies was observed over the central, south, and north of the Atlantic Ocean while the Pacific Ocean captured the El Nino Modoki (ENSO) like pattern in the SVD1 (SVD2). The heterogeneous correlation of Indian SST anomalies and rainfall over EA of the first (second) principal component (PC) shows a positive correlation over much of the domain (central region). The SST anomalies over the Pacific Ocean show higher correlation values with the rainfall over much of the study domain except over the southwestern highland and southern region of Tanzania. Over the Atlantic Ocean, the correlation result shows the patterns of positive (negative) values over the northern (southern) part for PC1, while PC2 depicts negative correlation values over much of the Ocean. SST anomalies over the Indian (Atlantic) Ocean are highly correlated with MAM rainfall when SST leads by 1(7) month(s). The Pacific Ocean shows a weak (strong) correlation across all (zero) lead seasons.
\end{abstract}

Keywords: SST; EA; MAM; Rainfall variability; SVD

\section{Introduction}

Rainfall is a very important parameter of weather and climate system in the region of EA. This is particularly common in the countries whose economy relies on rain-fed agriculture (Thornton et al., 2010; Ongoma et al., 2015; Brigadier et al., 2016), that contribute about
$40 \%$ of gross development product (GDP) and employs about $80 \%$ of the active population (Mikova, 2015; Ongoma \& Chen, 2017). Due to rainfall variability, the region of EA is affected by extreme weather events, such as floods and droughts (Anyah \& Semazzi, 2006; Ber-

\footnotetext{
A College of Atmospheric Sciences, Nanjing University of Information Science and Technology, 219 Ningliu Road, Nanjing, Jiangsu Province, P.R.C.,210044; kisesaexavery@yahoo.com; uadolatha@gmail.com; japhethlovina@yahoo.com; eliasjl2012@yandex. com; kebacho.laban@gmail.com; paul.limbu@ymail.com

B Physics Department, University of Dar es Salaam, P.O. Box 35063, Dar es Salaam, Tanzania.

C Rwanda Meteorology Agency, P.O. Box 898, Kigali, Rwanda

D Tanzania Meteorological Authority, P.O. Box 3056, Dar es Salaam, Tanzania

* Corresponding author: Laban Lameck Kebacho; email: kebacho.laban@gmail.com
} 
hane \& Zaitchik, 2014; MacLeod, 2018) which have impacts to the environmental and socio-economic activity of the region (IPCC, 2007; Ongoma, 2013).

The inter-annual rainfall variability over the region is attributed to the zonal circulation of the Indian ocean (Mafuru \& Guirong, 2018; Limbu \& Guirong, 2019). Previous studies discussed the influence of SST on seasonal rainfall variability over the region (Hastenrath et al., 2010; Mikova 2015). The same results have been found by Ngarukiyimana et al. (2018) and Camberlin (2018). During MAM rainfall season, the region receives intense rainfall due to the warmer SST in the western Indian ocean (Yang et al., 2015). The dry phases during the MAM season are associated with warmer SSTs over the western tropical Pacific and cooler SSTs over the central and eastern tropical Pacific (Lyon \& Dewitt 2012; Lyon et al., 2014; Yang et al., 2015). Thus, correspond to the intensification of Mascarene and Saint Helen anticyclones which trans- port the humidity air from the Atlantic Ocean passing through the Congo basin and Lake Kivu bringing the moisture and enhance precipitation over the region (Anyah \& Semazzi, 2006).

However, there are still many unresolved questions concerning the factors influencing MAM rainfall variability over EA meanwhile the prediction skill for MAM rainfall over the region is about $80 \%$ (Walker et al., 2019) which is not sufficient enough. This study aims to analyze how the SST varies with the rainfall over the region. The outcome of this study provides important information for climate services end users which help for reducing the vulnerability to the climate related destruction, damage, and losses.

The remaining parts are subdivided into the following sections: Data and methodology are detailed in section 2. The results and discussion are explained in the section 3 . The final remarks of this study are addressed as the conclusion in section 4 .

\section{Data and methodology}

\section{Data sources}

The gridded observation monthly precipitation dataset produced by the Climatic Research Unit (CRU) at the University of East Anglia was used in this study. The dataset is of version 4.03 (CRU TS 4.03) for the period 1981- 2018 covering the land surface at $0.5^{\circ} \times 0.5^{\circ}$ resolution. The same dataset taken from http://data. ceda.ac.uk/badc/cru/data/cru_ts/cru_ts_4.03/data/ pre was successfully used by Harris et al. (2019). Moreover, previous researchers used the CRU dataset to investigate the variability of rainfall over the study region (Ogwang et al.,2015; King'uza and Limbu, 2019). The SST dataset used is the Extended Reconstructed Sea Surface Temperature version 5 (ERSSTv5) with a resolution of $2^{\circ} \times 2^{\circ}$ from 1981 to 2018 . The dataset is acquired from the National Oceanic and Atmospheric Administration/ National Climatic Data Center, NOAA NCDC (http://iridl.ldeo.columbia.edu/ SOURCES/.NOAA/.NCDC/.ERSST/. version5/. sst) and was used by Huang et al. (2017). These datasets were used to analyze how the SST varies with rainfall over EA.

\section{Methodology}

The SVD was used to analyze the covariability between MAM precipitation over EA and the SST in the Tropical Oceans (i.e. Atlantic, Indian, and Pacific). The SVD approach has the advantage of evaluating the cross-covariance matrix of two spatial-temporal fields to identify regions of similar behaviour (Aziz et al., 2010). The same technique was used by (Ogwang et al., 2016; Ogou et al., 2016; Dubache et al.
2019; Li \& Zhao, 2019; Quishpe-Vásquez et al. 2019; $\mathrm{Li}$ et al., 2020) to investigate the response of rainfall on SST. This technique is applied to two jointly analysed fields to identify couples of the coupled spatial pattern and their respective temporal variations. The decomposition allows the extraction of dominant modes of the coupled covariability between the two analysed fields.

Correlation analysis was employed to reveal the simple relationships between two variables (Wilks, 2006). The Pearson's correlation coefficient ( $r$ ) is used as a good indicator of the strength of the relationship between the two fields. The same method was used by Cattani et al. (2018) and Kalisa et al. (2019) over the study region. From the SVD analysis, the heterogeneous correlation represents the correlation coefficients between the values of each grid point of the field and the expansion coefficients of the other field. In this study, the heterogeneous correlation indicates how well the pattern of the precipitation (SST) anomalies relates to the expansion coefficient of SST (precipitation). The anomaly was obtained by subtracting a value from its climatological mean (mean value from 1981 to 2010). The heterogeneous correlation was performed by projecting the temporal expansion series of each field onto the appropriate singular vector. The time lag correlation coefficient was used to find out in what time step the Atlantic, Indian and Pacific Oceans have a strong and significant linear relationship with East African's MAM rainfall. The same technique has been used by other researchers (Kug et al., 2006; Otte et al., 2017) in the region. 

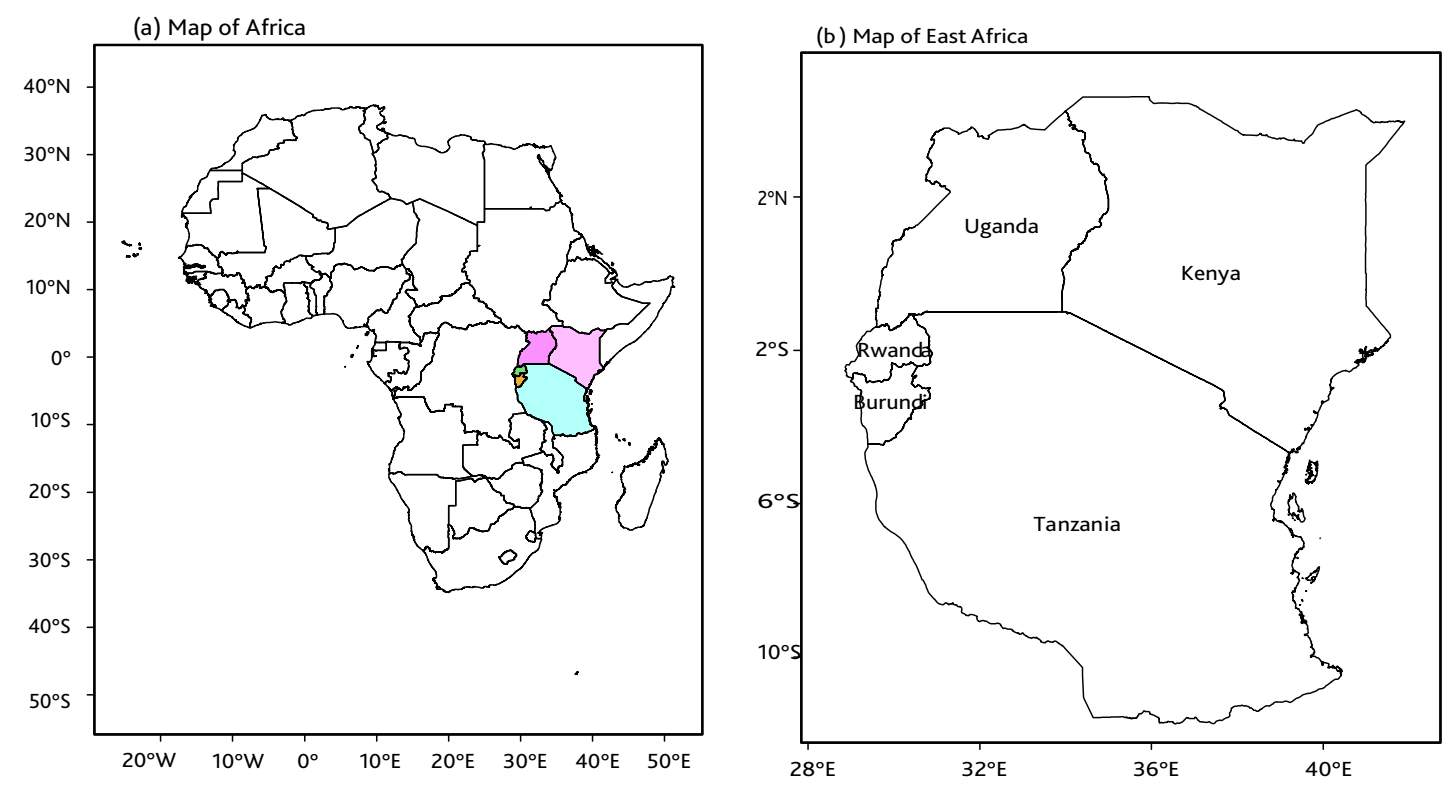

Figure 1. (a) Map of Africa showing the area of study (colored region)

(b) Map of East Africa showing countries used in this study

\section{Study area}

The EA region is located in the tropics bounded by a longitude of $280 \mathrm{E}$ to $420 \mathrm{E}$ and the latitude of $120 \mathrm{~S}$ to $50 \mathrm{~N}$ (Fig. 1b). EA includes Tanzania, Kenya, Uganda, Rwanda, and Burundi. The climate of East Africa is characterized by two rainy seasons regimes, short rainy season, October to December (OND), and long rainy season, MAM (Nicholson, 2014; Rowell et al., 2015). This bimodal regime is due to the northward and southward movement of the Intertropical Convergence Zone (ITCZ) (Muhire et al., 2015; Camberlin, 2018). EA climate varies from one place to another in accordance with geographical location, altitude, relief, and vegetation cover.

\section{Results}

The first two dominant coupled modes of SVD (Fig. 2) explain $88.61 \%$ of the total covariance, meaning that there is a good covariability between rainfall and SST over the Atlantic Ocean. The first SVD vector of precipitation in MAM (Fig. 2a) indicates the highest positive values over the South-east of Tanzania, which may be associated with positive SVD values over the northern Atlantic Ocean (where the Azores high is located) as well as negative values over the sub-tropical Atlantic Ocean (Fig. 2c). For the second SVD (Fig. 2b), the lowest negative values are featured over the southeast of Tanzania instead, and this is complemented by the disappearance of positive SVD values over the northern Atlantic Ocean where negative values have now dominated. However, still, negative values are over the subtropical Atlantic Ocean (Fig. 2d).

The first two dominant coupled modes of SVD explain $91 \%$ of the total covariance, meaning that there is a good covariability between rainfall and SST over the Indian Ocean (Fig. 3). There exist significant coupled modes of variability between SST in the Indian Ocean and the mean MAM rainfall over EA with the covariance of $83.9 \%$ of the first mode (SVD 1). SVD 1
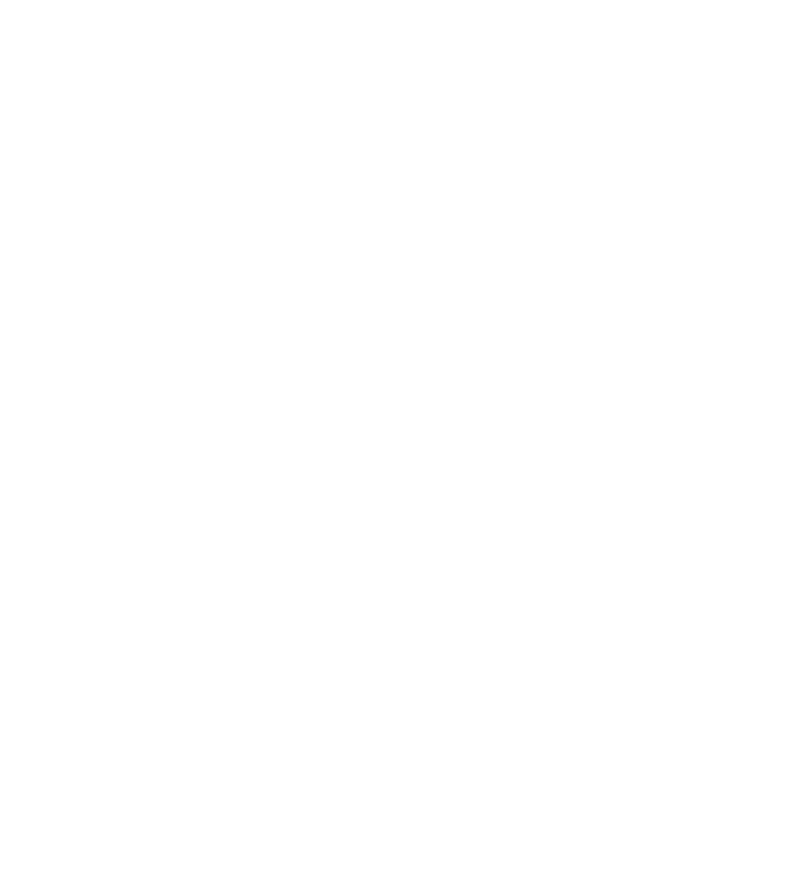

Figure 2. The homogeneous map of the first two modes of SVD for the Precipitation ( $\mathrm{mm} / \mathrm{month}$ ) ( $\mathrm{a}$ and $\mathrm{b}$ ) and SST $\left({ }^{\circ} \mathrm{C}\right.$ ) in an Atlantic Ocean (c and d). 

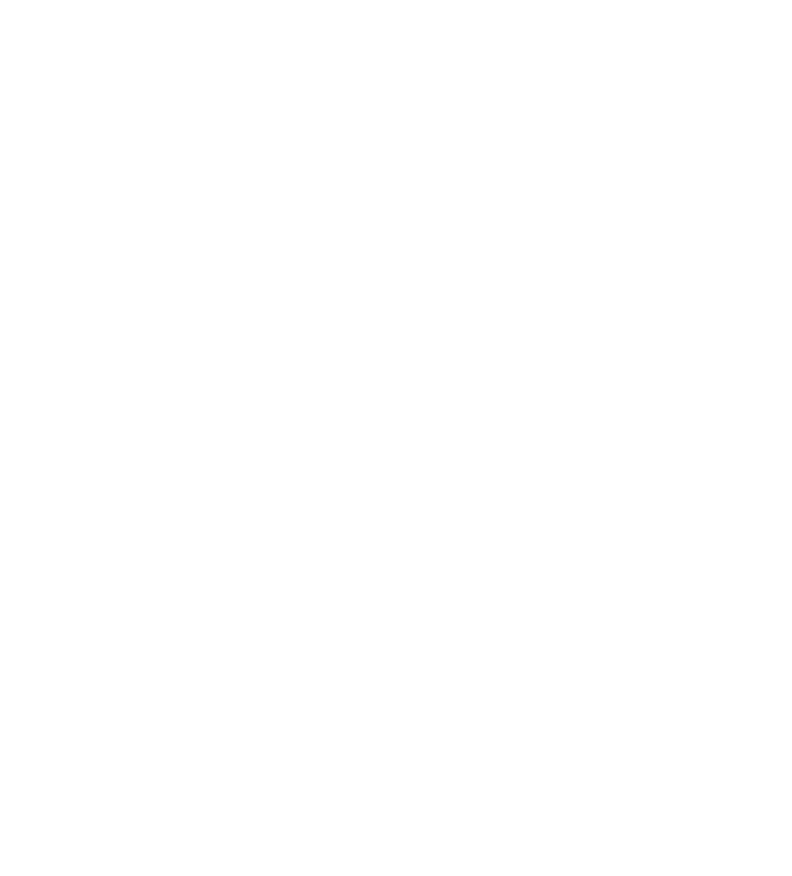

Figure 3. The homogeneous map of the first two modes of SVD for the Precipitation ( $\mathrm{mm} / \mathrm{month}$ ) ( $\mathrm{a}$ and $\mathrm{b}$ ) and SST $\left({ }^{\circ} \mathrm{C}\right.$ ) in an Indian Ocean (c and d)

(Fig. 3a) shows that the East African region is dominated by homogeneous positive loading all over the region with strong rainfall variability over the eastern coast and over the Lake Victoria basin. This is associated with positive loading SST anomalies (Fig. 3c) over the western and southwestern Indian Ocean and negative loading of SST anomalies over the central Indian Ocean.

SVD2 (Fig. 3b) depicts the presence of dipole patterns over the study area characterized by positive loading over the northern part extending towards the southwestern sectors, and negative loading over the eastern coast towards the southeastern and the western part of the Lake Victoria basin. The dipole pattern observed is associated with the dipole patterns of SST anomalies (Fig. 3d) over the Indian Ocean with positive loadings over the southeastern Indian Ocean and negative loadings over the remaining part of the Tropical Indian Ocean.

The first two dominant coupled modes of SVD explain $82.9 \%$ of the total covariance, meaning that there is a good covariability between rainfall and SST over the Pacific Ocean (Fig. 4). SVD 1 (Fig. 4a) depicts higher positive loading over bimodal rainfall regimes and the coastal belt of Tanzania. The same results persist in the southern region of Uganda including northern Lake Victoria while on the Kenyan side the loading occurs over the southwestern and coastal region. These loadings correspond with negative loadings over the central equatorial Pacific Ocean $\left(160^{\circ}-120^{\circ} \mathrm{W}\right)$ and other small SST anomalous over the Ocean (Fig. 4c). SVD 2 (Fig. 4b) re- veals diagonal positive loading of rainfall across EA and several positive loadings over the southern part of Tanzania, northern part, and the coast of Kenya. These loadings correspond with mixtures of weak positive and negative loadings over the Pacific Ocean (Fig. 4d). The remarkable feature is positive loading over the central eastern Pacific Ocean, which acts on opposite to SVD 1, this suggests the existence of a sea-saw pattern of SST anomalous over the region of El Nino Modoki. This gives a clue of a weak relationship between this region and rainfall over EA due to a weak correlation (0.41) on a temporal scale. Hence, Pacific Ocean SST is less related to MAM rainfall season over EA. Similar results were obtained by Preethi et al. (2015) which show that El Niño Modoki events are associated with suppressing of rainfall over eastern Africa.

The correlation between EA precipitation and PC1 and PC2 of SST anomaly shows that much of the central to northern parts of the region feature weak to moderate positive correlation (Fig. 5a\&b). The strongest values are indicated over northern Kenya as well as localized areas in Northern Tanzania, with correlation values as high as 0.4 . Otherwise, the rest of the region, mainly Southern parts, features very weak negative correlations. The correlation between SST over the Atlantic Ocean and $\mathrm{PC} 1$ of precipitation show positive values over the subtropical region of the Ocean and North of the Equator. Meanwhile, in the South of the Equator to the mid-latitude, there are negative values of correlation (Fig. 5c). However, further south, positive correlation values are evident. For PC2, there is hardly any clear pattern (Fig. 5d); a relatively high
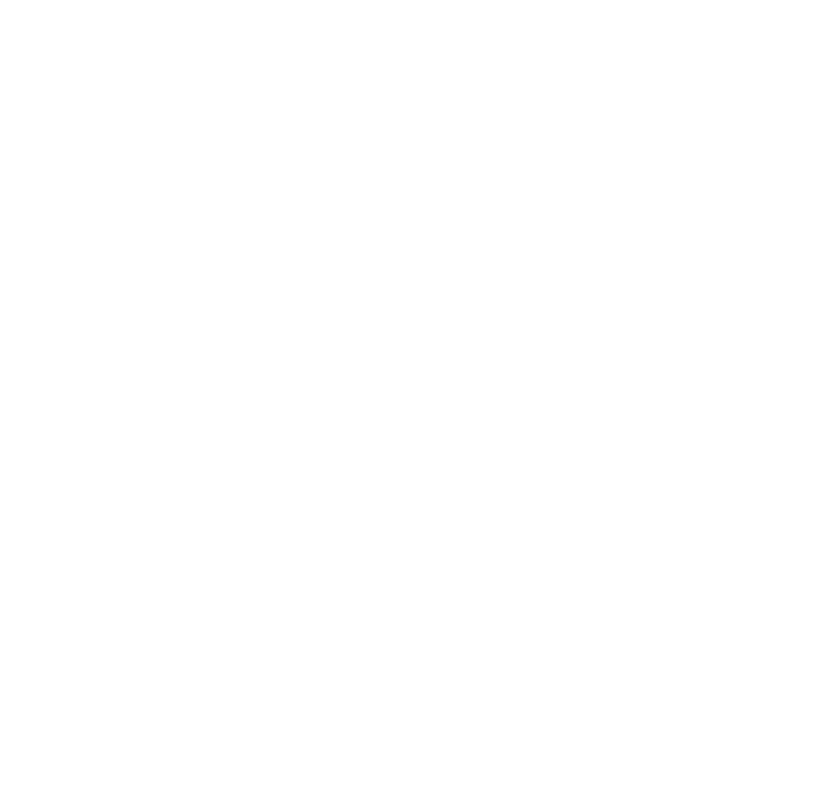

Figure 4. The homogeneous map of the first two modes of SVD for the Precipitation ( $\mathrm{mm} / \mathrm{month}$ ) ( $\mathrm{a}$ and $\mathrm{b}$ ) and SST $\left({ }^{\circ} \mathrm{C}\right.$ ) in Pacific Ocean (c and d) 

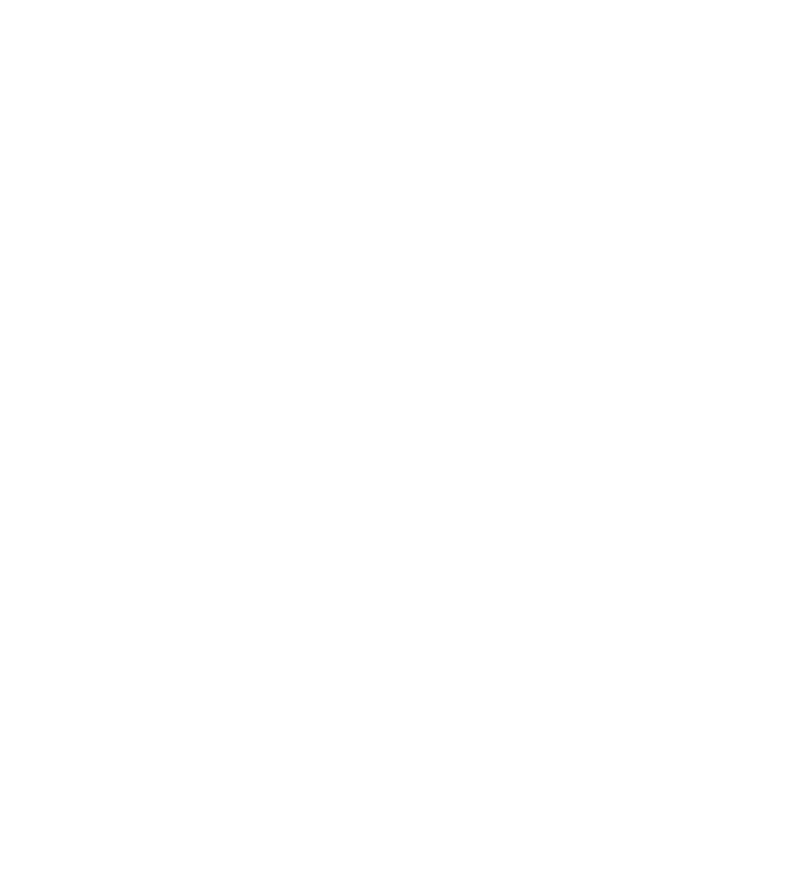

Figure 5. Heterogeneous correlation between

precipitation over the study area and PC 1 and 2 of

Atlantic SST ( $a$ and $b$ ) and heterogeneous correlation between Atlantic Ocean and PC 1 and 2 of precipitation (c and d)

negative correlation is over the sub-tropical region of the Western Atlantic Ocean (off the coast of Brazil) though.

For the Indian Ocean, a heterogeneous correlation of PC1 of SST anomaly is positively correlated with the EA rainfall over the northeastern extending towards the southwestern parts of the study area (Fig. $6 a)$. On the other hand, a negative correlation is observed over the remaining part. The PC2 of the SST anomaly is positively correlated with the EA rainfall almost all over the study area (Fig. 6b). Heterogeneous correlations of $\mathrm{PC} 1$ and $\mathrm{PC} 2$ of EA rainfall are negatively correlated with SST all over the Indian Ocean except the southeastern and maritime continent regions (Fig. $6 c \&$ d). This suggests the existing influence of western and southwestern parts of the Indian Ocean to MAM rainfall variability over the EA.

The heterogeneous correlation between EA rainfall and Principal components of Pacific Ocean SST was also analyzed. PC1 (Fig. 7a) shows the domination of positive correlation over much of the domain region except the southwestern highland and southern region of Tanzania where negative correlation is observed. PC2 (Fig. 7b), shows quite similar patterns to PC1; however, over portions of northeastern Tanzania, a positive correlation is replaced by a negative correlation which makes the area to resemble the dipole structure. Otherwise, in PC1, there are general-
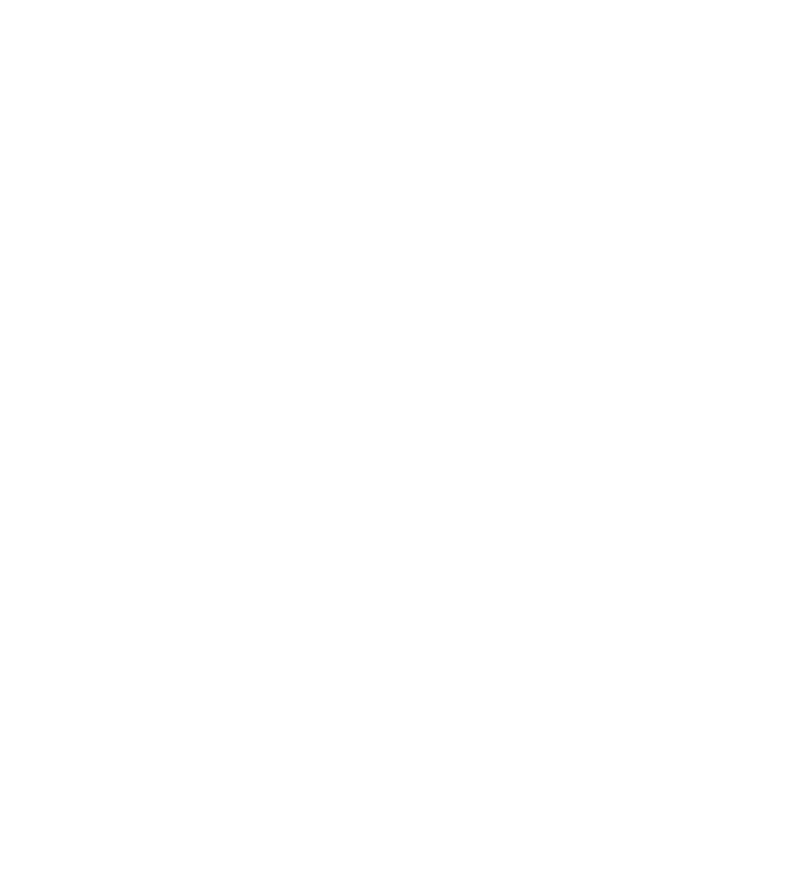

Figure 6. Heterogeneous correlation between precipitation over the study area and PC 1 and 2 of Indian SST ( $a$ and $b$ ) and heterogeneous correlation between Indian Ocean and PC 1 and 2 of precipitation (c and d)

ly higher correlation values over much of the domain. Likewise, the heterogeneous correlation between the Pacific Ocean SST and PC 1 and 2 of EA rainfall (Fig.
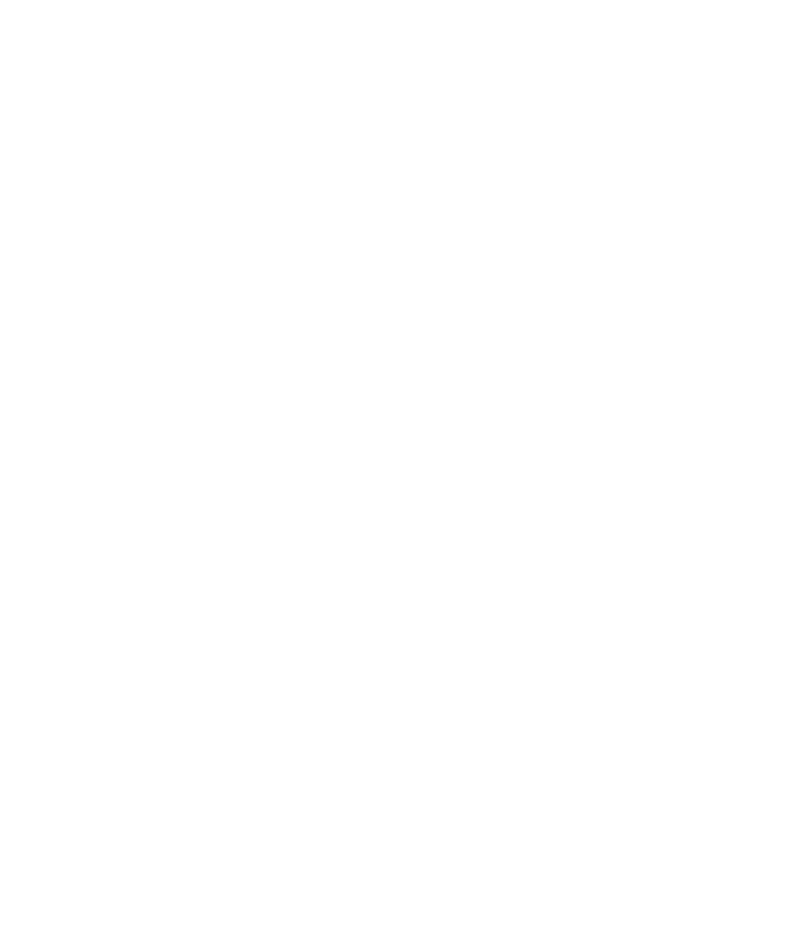

Figure 7. Heterogeneous correlation between precipitation over the study area and PC 1 and 2 of Pacific SST ( $a$ and $b$ ) and heterogeneous correlation between Pacific Ocean and PC 1 and 2 of precipitation (c and d) 


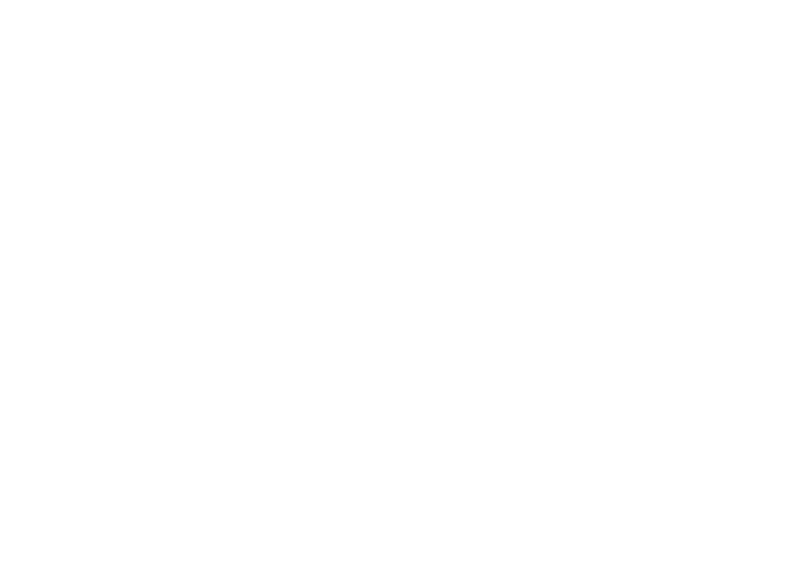

Figure 8. Lead correlation between precipitation and SST averaged over (a) Atlantic Ocean (b) Indian Ocean

7c\&d) shows a sea-saw pattern of SST anomalies over the central east Pacific Ocean (ENSO like pattern). The opposite SST patterns over the Pacific Ocean have a little relationship on changing rainfall patterns over East Africa but the figures give us the clue on which region over the Pacific Ocean has a stronger correlation to EA precipitation.
Looking into the lead-lag relationship between MAM precipitation over the EA and spatially averaged SST over the Atlantic Ocean, the results indicate that most significant correlation values are found in 7-month lead time i.e. during JJA (Fig. 8a). This is evident with negative values as low as around $-0.3 \mathrm{ob}$ served over some Southern areas of the Lake Victoria while positive correlation values as high as 0.3 observed over the area just north of the Lake Victoria over Uganda. In addition, along the coastal areas, mainly over Tanzania, negative values of correlation of down to -0.4 have been observed. The lead-lag correlation shows that the Indian Ocean SST has a fairly high correlation with MAM rainfall over EA when SST leads by 1 month i.e. during JFM (Fig. 8b), characterized by positive correlation all over the region except the eastern coastal region. As for the Pacific Ocean, the results generally show that the magnitude of positive correlation decreases slowly until replaced with negative correlation while moving toward previous seasons. The correlation coefficient values were weak across all leads; hence, we may say that SST over the Pacific Ocean has a little contribution to EA rainfall during MAM.

\section{Discussion}

The global Oceans SST has been found to have an influence on interannual and interdecadal variability of rainfall over different regions in the world. Changes in global SST over different regions may lead to intense rainfall or suppressed rainfall. The results from SVD analysis confirmed the complexity variability of rainfall over EA during the MAM rainfall season. SVD results have shown more insight into the modes of interannual rainfall variability over the region. The dominant modes representing zonal SST variability in the Indian Ocean which is consistent with other studies including Okoola (1996), Goddard and Graham (1999), Mutai (2003), Nyakwada (2009) among others. The study showed that MAM rainfall variability over EA is associated with warmer SST over the western Indian Ocean. The same result was found by Yang et al. (2015), where they documented that intense rainfall corresponds to warmer SST over the western Indian Ocean. It is also found that intense MAM rainfall is related to warmer SST over the northern Atlantic Ocean and vice versa. Moisture influx from the ocean is associated with an enhanced westerly circulation that also favours the incursions of moisture from the always wet tropical forests of Congo, Zaire, and other central African countries. The SST variability in the Atlantic Ocean reaches its maximum in the period from January to May (Wu et al., 2007). This may be due to the relaxation of Azores' high, which in turn, more moisture is pushed to the region with the aid of St. Helena high (Manatsa et al., 2014). Over the Pacific Ocean, the existence of El Nino Modoki over the central Pacific Ocean corresponds to positive rainfall anomalies over EA, especially over the bimodal regions. The result agrees with the study of Preethi et al. (2015) which explained that El Niño Modoki is associated with suppressing rainfall over eastern Africa. On the other hand, an ENSO-like pattern was captured in SVD 2 similar to that was shown by Kijazi and Reason (2005).

The characteristics of the SVD modes are closely related to some climate extremes affecting the region. These could be associated with the behaviour of these modes on the circulations, energy, and moisture induced by the ocean, and other inland generating systems. Barnston et al. (1996) explained that the time-space behaviour of the SST field alone influences the seasonal rainfall over the region both on different time-scales. This suggests that the large-scale changes in the global basins' SSTs have a significant influence on regional climate variability. To emphasize the importance of Oceans on regional climate variability, many studies have been done on the strong relationship between ocean currents and regional climate (Cai and Cowan, 2007; Keller et al., 2007; Valsala and 
Ikeda, 2007). The results in this study provide important information for improving the prediction skills of MAM rainfall over EA. Improvement in prediction skills will help to reduce the vulnerability to climaterelated destruction, damage, and losses. According to previous studies such as Lyon and DeWitt, (2012), and Ongoma and Chen (2017), MAM rainfall over EA shows a declining trend in the late 1990s. Therefore, we recommend future studies to focus on assessing the linkage of change in global SST especially on the regions identified with the declining trend of MAM rainfall over EA.

\section{Conclusion}

Results from this study point out the significant influence of SST anomalies over Indian, Pacific, and Atlantic Oceans on EA MAM rainfall seasonal variability. Indian, Atlantic, and the Pacific Ocean show good covariability of $91 \%, 88.61 \%$, and $82.9 \%$ with EA rainfall respectively. This indicates that the Indian Ocean explains the variability of rainfall to the large extent followed by the Atlantic Ocean and the Pacific Ocean.

The first two modes of SVD between SSTs and rainfall show similar rainfall patterns over eastern, eastern highlands, and Lake Victoria basin except SVD 2 which corresponding to the Pacific Ocean. The rainfall patterns over EA correspond to SST variability over the western, central, and eastern Indian Ocean. Additionally, the Atlantic Ocean depicts negative (positive) loading over central (south and north). However, the Pacific Ocean shows negative (positive) loading over central and eastern (eastern and western) in SVD1 and SVD2 respectively. SVD 1 (SVD 2) captured the El Nino Modoki-like (ENSO-like) pattern.

The heterogeneous correlation of Indian SST anomalies over EA rainfall of the first (second) PC shows positive correlations over much of the domain (central region). The PC's of EA rainfall anomalies were negatively correlated with SST anomalies over much of the Indian Ocean. Generally, the correlation between PC1 of Pacific SST anomalies and EA rainfall shows higher correlation values over much of the domain except over the southwestern highland and southern region of Tanzania. PC2 depicts a similar pattern with a northward extension of negative correlation. The correlation between the first and second PC of rainfall anomalies over the Pacific Ocean shows the ENSO-like pattern. Meanwhile, flip-flop patterns of correlation values were observed over the northern and southern Pacific Ocean. Over the Atlantic Ocean, the correlation result shows the dipole patterns of positive (negative) values over the northern (southern) part for PC1, while PC2 depicts negative correlation values over much of the Ocean. The lead correlation between the Indian Ocean SST shows high correlations with East Africa MAM rainfall when SST leads by 1 month. Meanwhile, the results indicate the most significant correlation values when SST leads by 7 months (during JJA) for the Atlantic Ocean. The Pacific Ocean shows a weak correlation across all lead seasons.

\section{Acknowledgements}

The authors wish to express their sincere thanks to Climatic Research Unit (CRU) at the University of East Anglia and National Oceanic and Atmospheric Administration/ National Climatic Data Center (NOAA NCDC) for making reanalysis data available. The authors are also grateful to Nanjing University of Information Sciences and Technology (NUIST) for providing a conducive environment and research facilities, without which this work could not have been possible.

\section{Conflict of interest}

The authors declare that there is no potential conflict of interest whatsoever.

\section{References}

Anyah, R. O., \& Semazzi, F. H. M. (2006). Climate variability over the Greater Horn of Africa based on NCAR AGCM ensemble. Theoretical and Applied Climatology, 86(1-4), 39-62. https://doi. org/10.1007/s00704-005-0203-7
Aziz, O. A., Tootle, G. A., Gray, S. T., \& Piechota, T. C. (2010). Identification of Pacific Ocean sea surface temperature influences of Upper Colorado River Basin snowpack. Water Resources Research, 46, W07536. https://doi.org/10.1029/2009WR008053 
Barnston, A. G., \& Smith, T. M. (1996). Specification and Prediction of Global Surface Temperature and Precipitation from Global SST Using CCA. Journal of Climate, 9(11), 2660-2697. https://doi. org/10.1175/1520-0442(1996)009<2660:SAPOGS $>$ 2.0.CO;2

Berhane, F., \& Zaitchik, B. (2014). Modulation of daily precipitation over East Africa by the MaddenJulian oscillation. Journal of Climate. https://doi. org/10.1175/JCLI-D-13-00693.1

Brigadier, L., Ogwang, B. A., Ongoma, V., Ngonga, C., \& Nyasa, L. (2016). Diagnosis of the 2010 DJF flood over Zambia. Natural Hazards, 81(1), 189-201. https://doi.org/10.1007/s11069-015-2069-Z

Cai, W., \& Cowan, T. (2007). Trends in Southern Hemisphere Circulation in IPCC AR4 Models over 1950-99: Ozone Depletion versus Greenhouse Forcing. Journal of Climate, 20(4), 681-693. https:// doi.org/10.1175/JCLI4028.1

Camberlin, P, \& Okoola, R. E. (2003). The onset and cessation of the " long rains "' in eastern Afri$\mathrm{ca}$ and their interannual variability. Theoretical and Applied Climatology. https://doi.org/10.1007/ s00704-002-0721-5

Camberlin, P. (2018). Climate of Eastern Africa. In Oxford Research Encyclopedia of Climate Science (pp. 1-51). https://doi.org/10.1093/acrefore/9780190228620.013.512

Camberlin, P., Moron, V., Okoola, R., Philippon, N., \& Gitau, W. (2009). Components of rainy seasons' variability in Equatorial East Africa: Onset, cessation, rainfall frequency and intensity. Theoretical and Applied Climatology. https://doi.org/10.1007/ s00704-009-0113-1

Cattani, E., Merino, A., \& Levizzani, V. (2018). Rainfall variability and trends over East Africa. 9th IPWG Workshop, Seoul, FP7 EC Project EartH2Observe.

Dubache, G., Ogwang, B. A., Ongoma, V., \& Towfiqul Islam, A. R. M. (2019). The effect of Indian Ocean on Ethiopian seasonal rainfall. Meteorology and Atmospheric Physics, 131(6), 1753-1761. https://doi. org/10.1007/s00703-019-00667-8

Goddard, L., \& Graham, N. E. (1999). Importance of the Indian Ocean for simulating rainfall anomalies over eastern and southern Africa. Journal of Geophysical Research: Atmospheres, 104(D16), 1909919116. https://doi.org/10.1029/1999JD900326

Harris, I.C., \& Jones, P. . (2019). CRU TS4.03: Climatic Research Unit (CRU) Time-Series (TS) version 4.03 of high-resolution gridded data of month-bymonth variation in climate (Jan. 1901- Dec. 2018). Centre for Environmental Data Analysis,https:// catalogue.ceda.ac.uk/uuid/10d3e3640f004c57. University of East Anglia Climatic Research Unit. https://doi.org/10.5285/58a8802721c94c66ae45c3b aa $4 \mathrm{~d} 814 \mathrm{~d} 0$

Hastenrath, S., Polzin, D., \& Mutai, C. (2010). Diagnosing the droughts and floods in equatorial east Africa during boreal autumn 2005-08. Journal of Climate 23(3), 813-817. https://doi.org/10.1175/2009JCLI3094.1

Huang, B., Thorne, P. W., Banzon, V. F., Boyer, T., Chepurin, G., Lawrimore, J. H., Menne, M.J., Smith, T.M., Vose, R.S., \& Zhang, H.-M. (2017). Extended Reconstructed Sea Surface Temperature, Version 5 (ERSSTv5): Upgrades, Validations, and Intercomparisons. Journal of Climate, 30(20), 8179-8205. https://doi.org/10.1175/JCLI-D-16-0836.1

IPCC. (2007). Summary for Policymakers. Climate Change 2007: The Physical Science Basis. Contribution of Working Group I to the Fourth Assessment Report of the Intergovernmental Panel on Climate Change. In Fourth Assessment Report of the Intergovernmental Panel on Climate Change. https://doi. org $/ 10.1038 / 446727 \mathrm{a}$

Kalisa, W., Igbawua, T., Henchiri, M., Ali, S., Zhang, S., Bai, Y., \& Zhang, J. (2019). Assessment of climate impact on vegetation dynamics over East Africa from 1982 to 2015. Scientific Reports, 9(1), 16865. https://doi.org/10.1038/s41598-019-53150-0

Keller, K., Deutsch, C., Hall, M. G., \& Bradford, D. F. (2007). Early Detection of Changes in the North Atlantic Meridional Overturning Circulation: Implications for the Design of Ocean Observation Systems. Journal of Climate, 20(2), 145-157. https:// doi.org/10.1175/JCLI3993.1

Kijazi, A. L., \& Reason, C. J. C. (2005). Relationships between intraseasonal rainfall variability of coastal Tanzania and ENSO. Theoretical and Applied Climatology, 82(3-4), 153-176. https://doi.org/10.1007/ s00704-005-0129-0

King'uza, P., \& Tilwebwa, S. (2019). Inter-annual variability of March to May rainfall over Tanzania and its association with atmospheric circulation anomalies. Geographica Pannonica, 23(3), 147-161. https://doi.org/10.5937/gp23-22430

Kug, J.-S., Kirtman, B. P., \& Kang, I.-S. (2006). Interactive Feedback between ENSO and the Indian Ocean in an Interactive Ensemble Coupled Model. Journal of Climate, 19(24), 6371-6381. https://doi. org/10.1175/JCLI3980.1

Li, C., Wang, C., \& Zhao, T. (2020). Seasonal Covariability of Dryness or Wetness in China and Global Sea Surface Temperature. Journal of Climate, 33(2), 727-747. https://doi.org/10.1175/JCLI-D-19-0250.1

Li, C., \& Zhao, T. (2019). Seasonal Responses of Precipitation in China to El Niño and Positive Indian Ocean Dipole Modes. Atmosphere, 10(7), 372. https://doi.org/10.3390/atmos10070372 
Limbu, P. T. S., \& Guirong, T. (2019). Relationship between the October-December rainfall in Tanzania and the Walker circulation cell over the Indian Ocean. Meteorologische Zeitschrift, 28(6), 453-469. https://doi.org/10.1127/metz/2019/0939

Lyon, B., Barnston, A. G., \& DeWitt, D. G. (2014). Tropical pacific forcing of a 1998-1999 climate shift: observational analysis and climate model results for the boreal spring season. Climate Dynamics, 43(3-4), 893-909. https://doi.org/10.1007/ s00382-013-1891-9

Lyon, B., \& Dewitt, D. G. (2012). A recent and abrupt decline in the East African long rains. Geophysical Research Letters, 39(2), 1-5. https://doi. org/10.1029/2011GL050337

Lyon, B., \& DeWitt, D. G. (2012). A recent and abrupt decline in the East African long rains. Geophysical Research Letters, 39(2). https://doi. org/10.1029/2011GL050337

MacLeod, D. (2018). Seasonal predictability of onset and cessation of the east African rains. Weather and Climate Extremes, 21, 27-35. https://doi. org/10.1016/j.wace.2018.05.003

Mafuru, K. B., \& Guirong, T. (2018). Assessing Prone Areas to Heavy Rainfall and the Impaction of the Upper Warm Temperature Anomaly during March-May Rainfall Season in Tanzania. Advances in Meteorology, 2018, 1-17. https://doi. org/10.1155/2018/8353296

Manatsa, D., Morioka, Y., Behera, S. K., Matarira, C. H., \& Yamagata, T. (2014). Impact of Mascarene High variability on the East African "short rains." Climate Dynamics, 42(5-6), 1259-1274. https://doi. org/10.1007/s00382-013-1848-Z

Mikova, K. (2015). Effect of Climate Change on Crop Production in Rwanda. Earth Sciences, 4(3), 120. https://doi.org/10.11648/j.earth.20150403.15

Muhire, I., Ahmed, F., Abutaleb, K., \& Kabera, G. (2015). Impacts of projected changes and variability in climatic data on major food crops yields in Rwanda. International Journal of Plant Production, 9(3).

Mutai, C. (2003). The role of Indian Ocean SST on East African Short rains. In Proceedings of the Sixth Kenya Meteorological Socety Workshop on Meteorology Research Applications and Services. Mombasa, Kenya, 29 September to 3 October 2003, 55- 59.

Mutai, C. C., \& Ward, M. N. (2000). East African Rainfall and the Tropical Circulation/Convection on Intraseasonal to Interannual Timescales. Journal of Climate, 13(22), 3915-3939. https://doi. org/10.1175/1520-0442(2000)013<3915:EARATT> 2.0.CO;2

Ngarukiyimana, J. P., Fu, Y., Yang, Y., Ogwang, B. A., Ongoma, V., \& Ntwali, D. (2018). Dominant at- mospheric circulation patterns associated with abnormal rainfall events over Rwanda, East Africa. International Journal of Climatology. https://doi. org/10.1002/joc.5169

Nicholson, S. E. (2014). A detailed look at the recent drought situation in the Greater Horn of Africa. Journal of Arid Environments, 103, 71-79. https:// doi.org/10.1016/j.jaridenv.2013.12.003

Nyakwada W. (2009). Predictability of East African Seasonal Rainfall with Sea Surface Temperature Gradient Modes. Doctor of Philosophy Dissertation, Department of Meteorology, University of Nairobi.

Ogallo, L. A. (1993). Dynamics of the East African climate. Proceedings of the Indian Academy of Sciences-Earth and Planetary Sciences, 102(1), 203-204.

Ogou, F.K, Batebana, K, Ogwang, B.A, Sein,Z.M.M,Ongoma, V \& Ngarukiyimana, J. (2016). Investigation of the Influence of Atlantic Ocean on Rainfall Variability over Benin Republic, West Africa. Ethiopia Journal of Environment Studieser Management, 9(1), 70-79.

Ogwang, B. A., Ongoma, V. \& Gitau, W. (2016). Contributions of Atlantic Ocean to June-August Rainfall over Uganda and Western Kenya. Journal of the Earth and Space and Physics, 41,(4), 131-140.

Okoola, R. E. (1996). Space-time characteristics of the itcz over equatorial eastern Africa during anomalous rainfall years. Retrieved from http://erepository.uonbi.ac.ke/handle/11295/20844

Ongoma, V. (2013). A review on the Effects of Climate Change on occurrence of Aflatoxin and its impacts on Food Security in Semi-Arid Areas of Kenya. International Journal of Agricultural Science Research, 2, 307-311.

Ongoma, V., \& Chen, H. (2017). Temporal and spatial variability of temperature and precipitation over East Africa from 1951 to 2010. Meteorology and Atmospheric Physics. https://doi.org/10.1007/s00703016-0462-0

Ongoma, V., Guirong, T., Ogwang, B., \& Ngarukiyimana, J. P. (2015). Diagnosis of Seasonal Rainfall Variability over East Africa: A Case Study of 20102011 Drought over Kenya. Pakistan Journal of Meteorology, 11(22), 13-21.

Otte, I., Detsch, F., Mwangomo, E., Hemp, A., Appelhans, T., \& Nauss, T. (2017). Multidecadal Trends and Interannual Variability of Rainfall as Observed from Five Lowland Stations at Mt. Kilimanjaro, Tanzania. Journal of Hydrometeorology, 18(2), 349-361. https://doi.org/10.1175/JHM-D-16-0062.1

Preethi, B., Sabin, T. P., Adedoyin, J. A., \& Ashok, K. (2015). Impacts of the ENSO Modoki and other Tropical Indo-Pacific Climate-Drivers on African Rainfall. Scientific Reports, 5(1), 16653. https://doi. org/10.1038/srep16653 
Quishpe-Vásquez, C., Gámiz-Fortis, S. R., García-Valdecasas-Ojeda, M., Castro-Díez, Y., \& Esteban-Parra, M. J. (2019). Tropical Pacific sea surface temperature influence on seasonal streamflow variability in Ecuador. International Journal of Climatology, 39(10), 3895-3914. https://doi.org/10.1002/joc.6047

Rowell, D. P., Booth, B. B. B., Nicholson, S. E., \& Good, P. (2015). Reconciling past and future rainfall trends over East Africa. Journal of Climate 28(24): 9768 9788. https://doi.org/10.1175/JCLI-D-15-0140.1

Thornton, P. K., Jones, P. G., Alagarswamy, G., Andresen, J., \& Herrero, M. (2010). Adapting to climate change: Agricultural system and household impacts in East Africa. Agricultural Systems, 103(2), 73-82. https://doi.org/10.1016/j.agsy.2009.09.003

Valsala, V. K., \& Ikeda, M. (2007). Pathways and Effects of the Indonesian Throughflow Water in the Indian Ocean Using Particle Trajectory and Trac- ers in an OGCM. Journal of Climate, 20(13), 29943017. https://doi.org/10.1175//CLI4167.1

Walker, D. P., Birch, C. E., Marsham, J. H., Scaife, A. A., Graham, R. J., \& Segele, Z. T. (2019). Skill of dynamical and GHACOF consensus seasonal forecasts of East African rainfall. Climate Dynamics, 53(7-8), 4911-4935. https://doi.org/10.1007/s00382$\underline{019-04835-9}$

Wilks, S. D. (2006). Statistical Methods in the Atmospheric Sciences. Academic Press, San Diego, 2nd Edn.

Wu, L., He, F., Liu, Z., \& Li, C. (2007). Atmospheric Teleconnections of Tropical Atlantic Variability: Interhemispheric, Tropical-Extratropical, and Cross-Basin Interactions. Journal of Climate, 20(5), 856-870. https://doi.org/10.1175/JCLI4019.1

Yang, W., Seager, R., Cane, M. A., \& Lyon, B. (2015). The annual cycle of east African precipitation. Journal of Climate, 28(6), 2385-2404 